\title{
Mammary gene expression and activity of antioxidant enzymes and oxidative indicators in the blood, milk, mammary tissue and ruminal fluid of dairy cows fed flax meal
}

\author{
Ana Luiza Bachmann Schogor ${ }^{1}$, Marie-France Palin ${ }^{2}$, Geraldo Tadeu dos Santos ${ }^{1}$, \\ Chaouki Benchaar ${ }^{2}$, Pierre Lacasse ${ }^{2}$ and Hélène V. Petit ${ }^{2 *}$ \\ ${ }^{1}$ Departamento de Zootecnia, Universidade Estadual de Maringa, Maringa, PR, Brazil \\ ${ }^{2}$ Dairy and Swine Research and Development Centre, Agriculture and Agri-Food Canada, \\ Sherbrooke, QC, Canada J1M OC8 \\ (Submitted 22 November 2012 - Final revision received 8 March 2013 - Accepted 13 March 2013 - First published online 12 April 2013)
}

\section{Abstract}

The effects of flax meal (FM) on the activity of antioxidant enzymes (superoxide dismutase (SOD), glutathione peroxidase (GPx) and catalase (CAT)) in the blood, mammary tissue and ruminal fluid, and oxidative stress indicators (thiobarbituric acid-reactive substances (TBARS) and 1,1-diphenyl-2-picrylhydrazyl-scavenging activity) in the milk, plasma and ruminal fluid of dairy cows were determined. The mRNA abundance of the antioxidant enzymes and oxidative stress-related genes was assessed in mammary tissue. A total of eight Holstein cows were used in a double $4 \times 4$ Latin square design. There were four treatments in the diet: control with no FM (CON) or 5\% FM (5FM), 10\% FM (10FM) and 15\% FM (15FM). There was an interaction between treatment and time for plasma GPx and CAT activities. Cows supplemented with FM had a linear reduction in TBARS at $2 \mathrm{~h}$ after feeding, and there was no treatment effect at 0,4 and $6 \mathrm{~h}$ after feeding. TBARS production decreased in the milk of cows fed the 5FM and 10FM diets. There was a linear increase in nuclear factor (erythroid-derived 2)-like 2 (NFE2L2) mRNA abundance in mammary tissue with FM supplementation. A linear trend for increased mRNA abundance of the $C A T$ gene was observed with higher concentrations of FM. The mRNA abundance of CAT, GPX1, GPX3, SOD1, SOD2, SOD3 and nuclear factor of $\kappa$ light polypeptide gene enhancer in B-cells (NFKB) genes was not affected by the treatment. These findings suggest that FM supplementation can improve the oxidative status of Holstein cows as suggested by decreased TBARS production in ruminal fluid $2 \mathrm{~h}$ post-feeding and increased NFE2L2/nuclear factor-E2-related factor 2 (Nrf2) mRNA abundance in mammary tissue.

\section{Key words: Catalase: 1,1-Diphenyl-2-picrylhydrazyl: Glutathione peroxidase: Superoxide dismutase: Thiobarbituric} acid-reactive substances

High-yielding dairy cows are prone to oxidative stress due to intensive metabolic demands for maintenance and production. This condition can be exacerbated under certain environmental, physiological and dietary factors ${ }^{(1,2)}$. Although lipid supplementation of ruminant diets with $n$-3 PUFA is a strategy to improve the nutritional quality of dairy products, this approach could increase the risk of plasma peroxidation with deleterious consequences on animal health ${ }^{(3)}$. Peroxidation results from oxidative metabolism, which is essential for the survival of cells. However, a side effect of this phenomenon is the production of free radicals and other reactive oxygen species that can cause oxidative damage ${ }^{(2)}$. Normally, the body is protected by a wide range of antioxidant systems working in concert with intracellular enzymes such as superoxide dismutase (SOD), glutathione peroxidase (GPx) and catalase (CAT), which remove superoxides and peroxides before they react with metal catalysts to form more reactive compounds ${ }^{(4)}$.

Lactation performance and antioxidant status of cows fed oxidised fat are enhanced when antioxidants are included in the diet ${ }^{(5)}$, which may be due to the scavenging of peroxides and the reduced peroxidation of fatty acids ${ }^{(6)}$. Supplementing antioxidants such as vitamin $\mathrm{E}$ and sodium selenite from early summer (e.g. the period characteristic of heat stress) may improve fertility through a decrease in cortisol secretion and oxidative stress, which enhances pregnancy rates in buffalo cows ${ }^{(7)}$. Moreover, strong positive correlations between several antioxidant enzymes (e.g. GPx) and pro-inflammatory

Abbreviations: 5FM, 5\% flax meal; 10FM, $10 \%$ flax meal; 15FM, $15 \%$ flax meal; CAT, catalase; CON, no flax meal; DPPH, 1,1-diphenyl-2-picrylhydrazyl; $\mathrm{EC}_{50}, 50 \%$ effective concentration; FM, flax meal; GPx, glutathione peroxidase; NFE2L2, nuclear factor (erythroid-derived 2)-like 2; SOD, superoxide dismutase; TBARS, thiobarbituric acid-reactive substances.

*Corresponding author: Dr H. V. Petit, email helene.petit@agr.gc.ca 
vascular adhesion molecules suggest a protective response of antioxidants to an enhanced pro-inflammatory state in transition dairy cows ${ }^{(8)}$. In addition, the study of Gobert et al. ${ }^{(3)}$ has shown that the association of plant polyphenols and vitamin E reduces plasma lipoperoxidation in dairy cows supplemented with a PUFA-rich diet. Antioxidants then could contribute to enhance defence mechanisms against oxidative stress with various immunity, reproductive and health benefits.

Plant lignans are natural strong antioxidants and flax (Linum usitatissimum) is known as the richest dietary source of lignans ${ }^{(9,10)}$. Flax lignans are metabolised by the rumen microbiota in mammalian lignans, which are transferred in the blood, milk and urine of dairy cows ${ }^{(11)}$. Prasad $^{(12)}$ reported that millimolar concentrations of the plant lignan secoisolariciresinol diglucoside and its mammalian metabolites enterodiol and enterolactone inhibit reactive oxygen species following an in vitro incubation of venous blood. This is of particular interest as many chronic diseases are characterised by an oxidative stress component ${ }^{(13)}$. More recently, Côrtes et $a l .^{(14)}$ have shown that flax hulls increase SOD activity and SOD1 mRNA abundance in the mammary tissue of dairy cows. These findings corroborate those of Rajesha et $a l .{ }^{(15)}$ who reported that flax antioxidants enhance rats' endogenous defence by up-regulating the expression of genes encoding for antioxidant enzymes such as SOD, CAT and GPX. As flax meal (FM) contains less than $5 \%$ of residual oil ${ }^{(16)}$, it is richer in plant lignans than in flaxseed on a DM basis, which makes it a better source of antioxidants. To our knowledge, there is no information available on the effect of FM on the activity and expression of antioxidant enzymes in dairy cows. We hypothesised that dietary FM modulates oxidative stress indicators in physiological fluids (e.g. blood, ruminal fluid and milk) and enhances those of oxidative status. We also postulated that FM contributes to extending the effect of treatment post-feeding. Therefore, the present study investigated the effects of increased concentrations of FM on the activity of SOD, CAT and GPx enzymes, 1,1-diphenyl2-picrylhydrazyl (DPPH) radical-scavenging activity and lipid peroxidation (thiobarbituric acid-reactive substance (TBARS) production) in the blood, milk, mammary tissue and ruminal fluid of dairy cows, and the mRNA abundance of oxidative stress-related genes in mammary tissue.

\section{Materials and methods}

\section{Animals and diets}

A total of eight multiparous Holstein cows fitted with a ruminal cannula $(10 \mathrm{~cm}$; Bar Diamond, Inc.) were assigned to four treatments in a double $4 \times 4$ Latin square design with four diets and four $21 \mathrm{~d}$ periods balanced for residual effects. Cows averaged 686 (SE 35) kg of body weight and 112 (sE 21) $\mathrm{d}$ in milk at the start of the experiment. The cows were housed in individual stalls and had free access to water. The diets were offered in equal amounts twice daily at 08.30 and 15.30 hours for ad libitum intake (10\% refusals on an as-fed basis) and they were milked twice daily at
08.00 and 19.00 hours. The diets were isonitrogenous and isoenergetic, and they were formulated to meet requirements for cows having $657 \mathrm{~kg}$ of body weight and producing $37.7 \mathrm{~kg}$ milk with $3 \cdot 8 \% \mathrm{fat} / \mathrm{d}^{(17)}$. The national guidelines for the care and use of animals were followed as recommended by the Canadian Council on Animal Care ${ }^{(18)}$. The four treatments (Table 1) were control with no FM (CON) or a pre-planned inclusion of $5 \%(5 \mathrm{FM}), 10 \%(10 \mathrm{FM})$ and $15 \%$ (15FM) FM in DM. The FM used in the present study was prepared using the expeller meal method (i.e. mechanical extraction of meal), which leaves about $5 \%$ of residual oil ${ }^{(16)}$.

\section{Experimental procedures}

Feed intake and milk yield were measured daily throughout the experiment, and data were averaged over the $7 \mathrm{~d}$ of the 4 th week of each period and subjected to ANOVA. Samples of the diet were taken once weekly and pooled within period. All samples were frozen at $-20^{\circ} \mathrm{C}$ for subsequent drying at $55^{\circ} \mathrm{C}$ and further analysis. On day 21 , milk samples were taken from two consecutive milkings, sampled in proportion to milk yield and pooled together. Of the two samples, one was stored at $4^{\circ} \mathrm{C}$ with a preservative (bronopol-B2; DNF Company) until analysed for fat, lactose, protein and urea N. Another sample was taken and $0.02 \%(\mathrm{w} / \mathrm{w})$ of sodium azide were added and kept frozen at $-80^{\circ} \mathrm{C}$ for further analysis of TBARS and DPPH.

Table 1. Ingredient and nutrient composition of the total mixed diets of Holstein cows fed no flax meal (CON) or $5 \%$ flax meal (5FM), $10 \%$ FM (10FM) and $15 \%$ FM (15FM)

\begin{tabular}{|c|c|c|c|c|}
\hline & \multicolumn{4}{|c|}{ Treatments } \\
\hline & CON & 5FM & $10 \mathrm{FM}$ & $15 \mathrm{FM}$ \\
\hline \multicolumn{5}{|l|}{ Ingredients (g/100 g DM) } \\
\hline Maize silage & 292 & 291 & 290 & 290 \\
\hline Grass silage & 315 & 316 & 317 & 314 \\
\hline Ground maize grain & 211 & 202 & 192 & 189 \\
\hline Soyabean meal & 108 & 74.5 & 41.4 & 20.4 \\
\hline Flax meal & 0 & $47 \cdot 9$ & $95 \cdot 3$ & 141 \\
\hline Top supplement* & $17 \cdot 4$ & $17 \cdot 4$ & $17 \cdot 9$ & 8.5 \\
\hline Beet pulp & $34 \cdot 3$ & $29 \cdot 6$ & $25 \cdot 0$ & $16 \cdot 1$ \\
\hline Calcium carbonate & 5.5 & $5 \cdot 5$ & 5.4 & $5 \cdot 5$ \\
\hline Minerals and vitamins $\dagger$ & $16 \cdot 4$ & $16 \cdot 3$ & $16 \cdot 3$ & $15 \cdot 5$ \\
\hline \multicolumn{5}{|l|}{ Chemical composition $\ddagger$} \\
\hline $\mathrm{DM}$ (g/100 g diet) & $37 \cdot 7$ & 37.9 & $37 \cdot 6$ & $38 \cdot 1$ \\
\hline Crude protein (g/100 g DM) & $17 \cdot 0$ & $17 \cdot 4$ & $17 \cdot 6$ & $17 \cdot 9$ \\
\hline Fat (g/100 g DM) & $2 \cdot 44$ & $2 \cdot 41$ & $2 \cdot 34$ & $2 \cdot 41$ \\
\hline $\begin{array}{l}\text { Acid-detergent fibre } \\
\text { (g/100 g DM) }\end{array}$ & $18 \cdot 3$ & $18 \cdot 5$ & $19 \cdot 2$ & $19 \cdot 3$ \\
\hline $\begin{array}{l}\text { Neutral-detergent fibre } \\
\text { (g/100 g DM) }\end{array}$ & 28.4 & $28 \cdot 6$ & 29.5 & $29 \cdot 6$ \\
\hline $\begin{array}{l}\text { Net energy for lactation } \\
(\mathrm{kJ} / \mathrm{g} \mathrm{DM}) \S\end{array}$ & 6.65 & $6 \cdot 61$ & $6 \cdot 61$ & $6 \cdot 61$ \\
\hline
\end{tabular}

${ }^{*}$ Contained $20 \%$ of rapeseed meal, $30 \%$ of maize gluten meal, $20 \%$ of soyabean meal and $30 \%$ of brewer's maize.

†The premix contained (per kg of premix): Ca $92 \mathrm{~g}$; P $47.9 \mathrm{~g}$; Mg $47.8 \mathrm{~g}$; S $15.2 \mathrm{~g}$; $\mathrm{Na} 137.2 \mathrm{~g} ; \mathrm{K}$ 13.7g; Se 19.5 mg; I $23 \mathrm{mg}$; Fe 2013 mg; Cu $1068 \mathrm{mg} ; \mathrm{Mn}$ $1796 \mathrm{mg}$; Zn $2657 \mathrm{mg}$; Co $57 \mathrm{mg}$; F $265 \mathrm{mg}$; vitamin A $442000 \mathrm{IU}(463.1 \mu \mathrm{mol} / \mathrm{l})$; vitamin $D_{3} 56670 \mathrm{IU}$ (3536208 $\left.\mathrm{nmol} / \mathrm{l}\right)$; vitamin E $2630 \mathrm{IU}(40986 \mu \mathrm{mol} / \mathrm{l})$.

$\ddagger$ Mean of four samples that were prepared by compositing three samples collected once per week and pooled within period.

$\S$ Calculated using the published values of feed ingredients ${ }^{(17)}$. 
On day 20 of each period, blood samples $(60 \mathrm{ml})$ were collected immediately before the morning meal and $3 \mathrm{~h}$ postfeeding from the caudal vein into vacutainer tubes (Becton Dickinson and Cie) containing $\mathrm{K}_{3}$-EDTA $(0.47 \mathrm{~mol} / \mathrm{l})^{(3)}$. Plasma was isolated from the blood by centrifugation at $3000 \mathrm{~g}$ for $12 \mathrm{~min}$ at $4^{\circ} \mathrm{C}$ and stored at $-80^{\circ} \mathrm{C}$ to determine enzyme activities, TBARS and DPPH. The remaining erythrocytes were stored at $-80^{\circ} \mathrm{C}$ for subsequent analysis of enzyme activity. Biopsies of the mammary gland were taken on day 21 of each period using the method of Farr et al. ${ }^{(19)}$ and alternating between the left and right hindquarters. Although inflammation was restricted to a very small area and disappeared within $2 \mathrm{~d}$, a site at least $10 \mathrm{~cm}$ apart from the first one was chosen when a quarter was used for the second time. Tissue obtained from the biopsies was rinsed in sterile saline solution to remove all traces of blood, and then cut into two parts: one was immediately frozen in liquid $\mathrm{N}_{2}$ and stored at $-80^{\circ} \mathrm{C}$ for gene expression analyses. The other half was ground immediately with a rotor-stator homogeniser and stored at $-80^{\circ} \mathrm{C}$ for further analysis of antioxidant enzyme activity.

On day 20, ruminal contents were collected at 0 (immediately before the distribution of the meal), 2, 4 and $6 \mathrm{~h}$ after the morning meal from different locations within the rumen (anterior dorsal, anterior ventral, medium ventral, posterior dorsal and posterior ventral locations) to obtain representative samples. The ruminal contents were then strained through four layers of cheesecloth, and the filtered ruminal fluid of each sampling time was stored at $-80^{\circ} \mathrm{C}$ for further chemical analysis. Ruminal liquid was thawed later and one portion was used to determine TBARS production. Another portion was centrifuged at $800 \mathrm{~g}$ for $10 \mathrm{~min}$ at $4^{\circ} \mathrm{C}$ to remove protozoa. The supernatant was taken and centrifuged at $13700 \mathrm{~g}$ for $25 \mathrm{~min}$ at $4^{\circ} \mathrm{C}$ to remove the debris of bacteria (Sorvall RC-6 Plus Superspeed Centrifuge; Thermo Scientific) and was used directly to analyse the activity of antioxidant enzymes. For DPPH analysis, $75 \mu \mathrm{l}$ of the supernatant were mixed with methanol $(2.55 \mathrm{ml})$ during $30 \mathrm{~s}$ and centrifuged at $9809 \mathrm{~g}$ for $15 \mathrm{~min}$, and the upper layer was used to perform DPPH analysis.

\section{Chemical analysis}

Concentrations of DM, diethyl ether extract, acid-detergent fibre, neutral-detergent fibre and total $\mathrm{N}$ in the diets were analysed according to the procedures described by Côrtes et $a{ }^{(14)}$. Fat, lactose, protein and urea $\mathrm{N}$ concentrations in the milk samples were analysed by IR spectrophotometry (System 4000 Milkoscan; Foss Electric of Hillerod) following procedure 972.16 of AOAC (1990). Somatic cells were counted using an optical somatic cell counter (Fossomatic 90; Foss Electric of Hillerod).

The activity of GPx (EC 1.11.1.9), SOD (EC 1.15.1.1) and CAT (EC 1.11.1.6) in plasma, erythrocytes, ruminal fluid and mammary tissue was determined enzymatically. Activities of SOD, CAT and GPx were analysed using commercial assay kits (Cayman Chemical) according to the manufacturer's instructions. Details of these analyses have been described previously ${ }^{(14)}$. The maximum intra- and inter-assay $\mathrm{CV}$ for SOD and GPX analyses were 10 and $10 \%$, respectively, while the maximum intra- and inter-assay coefficients of CAT were 12.5 and $10 \cdot 1 \%$. Total protein concentration in plasma, erythrocytes, ruminal fluid and mammary tissue was determined with a bicinchoninic acid protein assay (Sigma-Aldrich).

Determination of DPPH in plasma, ruminal fluid and milk was done according to the procedures of Brand-Williams et $a l .{ }^{(20)}$ and Martinez et $a l .{ }^{(21)}$ using a stable free-radical $\mathrm{DPPH}$, with some modifications. Concentration of the DPPH (Sigma-Aldrich D9132) solution was $200 \mu \mathrm{M}$ in methanol, prepared $1 \mathrm{~h}$ before use, and samples were read in polypropylene ninety-six-well plates. Concentration of the DPPH solution was the same for plasma, milk and ruminal fluid. Plasma samples were prepared according to Martinez et al. ${ }^{(21)}$. Milk extracts were prepared by mixing $0.75 \mathrm{ml}$ milk and $3 \mathrm{ml}$ methanol. The samples were then vortex mixed for $15 \mathrm{~s}$ at high speed and kept at $-20^{\circ} \mathrm{C}$ for $48 \mathrm{~h}$. The milk extract was then centrifuged at $2000 \mathrm{~g}$ for $15 \mathrm{~min}$ at $4^{\circ} \mathrm{C}$, and the supernatant was used to perform the DPPH analysis. For each sample, five different volumes of the milk extract (50, $100,125,250$ and $500 \mu \mathrm{l}$ ) were added to $500 \mu \mathrm{l}$ of the DPPH solution, and dilutions were done in duplicate. An aliquot of $250 \mu \mathrm{l}$ of each dilution was placed in a ninety-six-well plate as well as $250 \mu \mathrm{l}$ of the DPPH solution (control) and $250 \mu \mathrm{l}$ methanol (blank). The reduction in DPPH was determined at $515 \mathrm{~nm}$ after $30 \mathrm{~min}$ for plasma and milk, and after $25 \mathrm{~min}$ for ruminal fluid. The assay was performed in triplicate. Antioxidant capacity was calculated according to the method of Li et $a l^{(22)}$. A linear relationship was obtained between antioxidant capacity and the volume dilution of samples as described by Smet et al. ${ }^{(23)}$, and the $50 \%$ effective concentration $\left(\mathrm{EC}_{50}\right)$ was calculated. Lipid peroxidation was assessed in plasma, ruminal fluid and milk in the original samples using a commercially available TBARS assay kit (OXI-TEK TBARS Assay Kit; Zepto Metrix Company) according to the manufacturer's instructions.

\section{Quantitative real-time RT-PCR amplifications of the studied genes}

Total RNA was extracted from the mammary tissue and complementary DNA synthesis was performed as described previously ${ }^{(24)}$. Integrity of the extracted RNA was assessed by verifying the presence of $18 \mathrm{~S}$ and $28 \mathrm{~S}$ RNA bands after electrophoresis on a $1 \%$ agarose gel. Purity of the extracted RNA was assessed by measuring the $260 / 280$ absorbance ratio with a NanoDrop ND-1000 spectrophotometer (NanoDrop Technologies, Inc.). The average $260 / 280$ ratio of the extracted RNA samples was $2 \cdot 01(1.97-2 \cdot 04)$, thus confirming RNA purity of our samples. The relative mRNA abundance of the studied genes was determined using quantitative real-time PCR amplification. Quantitative PCR amplification, detection and data analyses were performed using an ABI 7500 Fast Real-time PCR System (PE Applied Biosystems). Primer pairs were designed using Primer Express software 3.0 (PE Applied Biosystems). A detailed description of primer sequences, GenBank accession numbers and amplified product size of the CAT, SOD1, 
SOD2, SOD3, GPX1 and GPX3 genes has been published previously $^{(14)}$. Forward 5'-GTACCCCTGGAAATGTCAAACAG- $3^{\prime}$ and reverse 5'-TGTGATGACGACAAAGGTTGGA- $3^{\prime}$ primers (NM_001011678, 88bp amplicon) were used for the nuclear factor (erythroid-derived 2)-like 2 (NFE2L2) gene, and the primer pair forward 5'-CTCAAAGCAGCAGGAGCAGA-3' and reverse 5'-CGGTACGACCCCTTCATCC-3' (NM_001076409, $102 \mathrm{bp}$ amplicon) was used for the nuclear factor of $\kappa$ light polypeptide gene enhancer in B-cells $(N F K B)$ gene. To minimise non-specific amplification, primer optimisation tests were first performed for each gene to determine the minimum primer concentration needed for having the lowest threshold cycle and the maximum change in fluorescence (normalised reporter signal; $\Delta \mathrm{Rn}$ ). Quantitative PCR amplifications were carried out in a $10 \mu \mathrm{l}$ reaction volume containing primers (final concentrations ranging from 150 to $900 \mathrm{~nm}$ ), $5 \mu$ l of $2 \times$ Power SYBR Green Master Mix (PE Applied Biosystems), $3 \mu$ l of $15 \times$ diluted complementary DNA and $0.05 \mu$ l of AmpErase (PE Applied Biosystems). Cycling conditions were $2 \mathrm{~min}$ at $50^{\circ} \mathrm{C}$, followed by $10 \mathrm{~min}$ at $95^{\circ} \mathrm{C}$ and forty cycles of $3 \mathrm{~s}$ at $95^{\circ} \mathrm{C}$ and $30 \mathrm{~s}$ at $60^{\circ} \mathrm{C}$. Specificity of amplified fragments was determined for all genes using the melting curve (dissociation curve) analysis. Amplification of the reference genes glyceraldehyde-3-phosphate dehydrogenase (GAPDH), peptidylpropyl isomerase A $(P P I A)$, actin $\beta(A C T B)^{(14)}$ and polyubiquitin (forward $5^{\prime}-\mathrm{TGG}$ AGCCCAGTGACACCAT- $3^{\prime}$ and reverse $5^{\prime}$-GGCCATCTTCCAGCTGCTT-3' primers, NM_174133, 111 bp amplicon) was also performed, and the NormFinder algorithm ${ }^{(25)}$ was then used to identify the least affected by the treatments. Polyubiquitin was identified as the best reference gene for normalisation of datasets in the present study. Quantitative PCR amplifications were performed in triplicate and standard curves were established in duplicate for each gene. Standard curves were composed of serial dilutions of complementary DNA pools ${ }^{(24)}$, and were used to obtain the relative mRNA abundance of the studied genes using the standard curve method as described by Applied Biosystems ${ }^{(26)}$.

\section{Statistical analysis}

All data were analysed as a $4 \times 4$ double Latin square design using the MIXED procedure of SAS, release 9.2 (SAS 2002; SAS Institute) according to the model:

$$
Y_{i j k l}=\mu+T_{i}+P_{j}+Q_{k}+A / Q_{k l}+e_{i j k l},
$$

where $Y_{i j k l}$ is the response variable; $\mu$ is the overall mean; $T_{i}$ is the global effect of treatment $(i=\mathrm{CON}, 5 \mathrm{FM}, 10 \mathrm{FM}$ and $15 \mathrm{FM}) ; P_{j}$ is the fixed effect of period $(j=1-4) ; Q_{k}$ is the fixed effect of square $(k=1,2) ; A / Q_{k l}$ is the random effect of cow within square; $e_{i j k l}$ is the residual error. The treatments were compared by contrasts in order to test the polynomial effects (linear, quadratic and cubic) of FM. Data on TBARS, DPPH and enzyme activities in plasma, ruminal fluid, erythrocytes and milk were analysed as repeated measurements and the compound symmetry was used as the covariance structure. The Shapiro-Wilk test was used to check normality between the data obtained at different sampling times. When a tendency was observed for an interaction $(P \leq 0 \cdot 10)$ between treatment and time, the effect of treatment was examined within each time group, and then the treatment effects were compared at the relevant time. Similar approaches were performed by Barret et al. ${ }^{(27)}$. Differences were declared significant when $P \leq 0 \cdot 05$, and a trend when $0 \cdot 05<P \leq 0 \cdot 10$.

\section{Results}

There was a linear effect of treatment on DM intake as a result of higher intake with an increased level of FM in the diet (Table 2). The concentration of FM in the diet had no effect on milk production, the composition and yield of milk components and feed efficiency (Table 2). The only exception was the proportion of lactose in milk that showed linear $(P=0 \cdot 10)$, quadratic $(P=0.03)$ and cubic $(P=0.09)$ effects with an increasing level of FM in the diet.

The production of TBARS, expressed in terms of malondialdehyde equivalents $(\mathrm{nmol} / \mathrm{ml})$, was lower in the milk of cows

Table 2. DM intake (DMI), milk yield and milk composition of Holstein cows fed no flax meal (CON) or $5 \%$ flax meal (5FM), $10 \%$ FM (10FM) and $15 \%$ FM (15FM)

\begin{tabular}{|c|c|c|c|c|c|c|c|c|}
\hline & \multicolumn{4}{|c|}{ Treatments } & \multirow[b]{2}{*}{ SEM } & \multicolumn{3}{|c|}{$P$ (treatment effects) } \\
\hline & CON & $5 F M$ & $10 \mathrm{FM}$ & $15 \mathrm{FM}$ & & Linear & Quadratic & Cubic \\
\hline $\mathrm{DMI}(\mathrm{kg} / \mathrm{d})$ & 21.0 & $20 \cdot 3$ & $21 \cdot 1$ & $22 \cdot 0$ & 0.3 & 0.01 & 0.14 & 0.01 \\
\hline DMI (\% of body weight) & 3.03 & 3.03 & $3 \cdot 17$ & $3 \cdot 27$ & 0.07 & 0.01 & 0.50 & 0.08 \\
\hline Milk yield $(\mathrm{kg} / \mathrm{d})$ & 35.5 & $36 \cdot 5$ & $36 \cdot 0$ & $36 \cdot 0$ & 0.8 & 0.76 & 0.54 & 0.60 \\
\hline Feed efficiency (kg milk/kg DM) & 1.70 & 1.73 & 1.69 & 1.68 & 0.03 & 0.33 & 0.45 & 0.22 \\
\hline \multicolumn{9}{|l|}{ Milk composition (\%) } \\
\hline Fat & 3.69 & 3.57 & 3.40 & 3.63 & 0.09 & 0.36 & 0.07 & 0.28 \\
\hline Lactose & 4.49 & $4 \cdot 60$ & 4.57 & 4.56 & 0.02 & $0 \cdot 10$ & 0.03 & 0.09 \\
\hline Protein & 3.58 & 3.52 & 3.55 & 3.53 & 0.03 & 0.32 & 0.47 & 0.67 \\
\hline Urea $\mathrm{N}$ & $10 \cdot 8$ & $10 \cdot 7$ & $10 \cdot 4$ & $11 \cdot 3$ & 0.6 & 0.71 & 0.43 & 0.44 \\
\hline Total solids & $12 \cdot 7$ & $12 \cdot 7$ & $12 \cdot 5$ & $12 \cdot 7$ & 0.1 & 0.45 & 0.17 & 0.48 \\
\hline \multicolumn{9}{|l|}{ Yield of milk components $(\mathrm{kg} / \mathrm{d})$} \\
\hline Fat & 1.32 & 1.27 & 1.24 & 1.29 & 0.03 & 0.40 & 0.14 & 0.35 \\
\hline Lactose & 1.63 & 1.66 & 1.69 & 1.65 & 0.04 & 0.60 & 0.33 & 0.55 \\
\hline Protein & 1.28 & 1.25 & 1.29 & 1.25 & 0.03 & 0.76 & 0.93 & 0.98 \\
\hline Total solids & 4.58 & 4.53 & 4.58 & 4.54 & 0.09 & 0.85 & 0.93 & 0.92 \\
\hline Somatic cell score* & 1.19 & 1.61 & 2.03 & 2.02 & 0.38 & $0 \cdot 10$ & 0.57 & 0.82 \\
\hline
\end{tabular}

${ }^{*} \log _{10}$ (somatic cell count). 
(a)

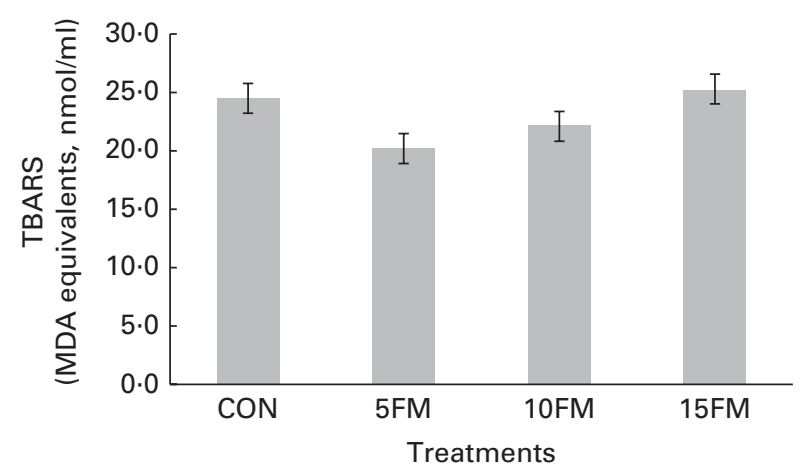

(b)

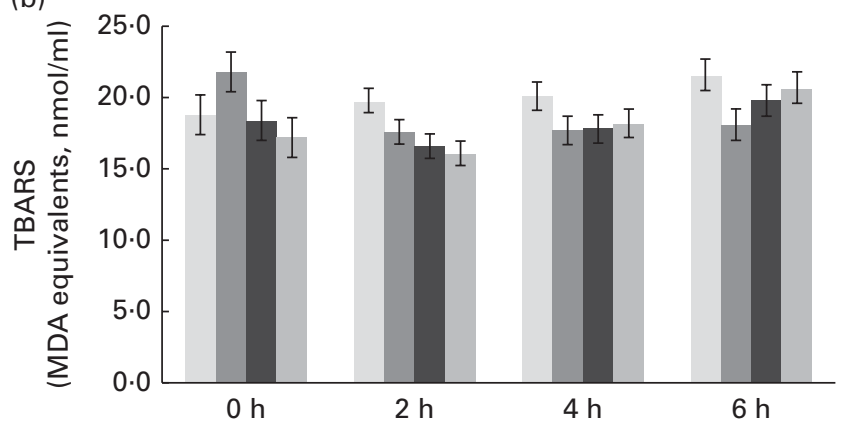

Fig. 1. Thiobarbituric acid-reactive substance (TBARS) production (malondialdehyde (MDA) equivalents) in (a) the milk and (b) ruminal fluid of Holstein cows fed no flax meal (CON, $)$ ), or $5 \%$ flax meal $(5 F M, \square)$, $10 \% \mathrm{FM}(10 \mathrm{FM}, \mathrm{n})$ and $15 \% \mathrm{FM}(15 \mathrm{FM}, \square)$ in the diet. Values are means, with their standard errors represented by vertical bars. Standard errors were 1.28 for milk. Standard errors were $1.39,0.85,0.99$ and 1.10 for $0,2,4$ and $6 \mathrm{~h}$ after feeding, respectively, for ruminal liquid. Production of TBARS was lower in the milk of cows fed 5FM and 10FM than in the milk of those fed the $\mathrm{CON}$ and 15FM diets as a result of quadratic $(P=0.009)$ and cubic $(P=0.006)$ effects of treatment. There was an interaction $(P=0.01)$ between time and treatment for TBARS production in ruminal fluid.

fed the 5FM and 10FM diets than in the milk of those fed the CON and 15FM diets, as shown by quadratic $(P=0.009)$ and cubic $(P=0.006)$ effects of treatment (Fig. 1(a)).

FM supplementation had no effect on TBARS production in plasma $(P=0.43)$, with average values of $3.60,4.05,3.90$ and $4.05(\mathrm{se} 0.28) \mathrm{nmol} / \mathrm{ml}$ for the CON, 5FM, 10FM and $15 \mathrm{FM}$ diets, respectively. However, the concentration of TBARS in plasma was reduced $(P=0 \cdot 04)$ at $3 \mathrm{~h}$ after feeding, regardless of FM supplementation, with mean values of $4 \cdot 1$ and $3.7 \mathrm{nmol} / \mathrm{ml}$ at 0 and $3 \mathrm{~h}$, respectively.

There was an interaction $(P=0 \cdot 01)$ between time and treatment for TBARS measurement in ruminal fluid. When cows were supplemented with FM, there was a linear $(P=0 \cdot 01)$ reduction in TBARS at $2 \mathrm{~h}$ after feeding, and there were no treatment effects at 0,4 and $6 \mathrm{~h}$ after feeding (Fig. 1(b)).

Radical-scavenging activities determined in milk, plasma and ruminal fluid by the DPPH assay were not affected by FM supplementation. The values of $\mathrm{EC}_{50}$ were similar among the diets and averaged $26.70,46.50$ and $8.67 \mu \mathrm{l} / \mathrm{ml}$, respectively, in milk, plasma and ruminal fluid. Regardless of the treatment, there was a time effect on DPPH in ruminal fluid $(P<0.001)$. The mean values of $\mathrm{EC}_{50}$ in ruminal fluid at $0,2,4$ and $6 \mathrm{~h}$ after feeding were $11 \cdot 1,10 \cdot 8,10 \cdot 6$ and $10 \cdot 8 \mu \mathrm{l} / \mathrm{ml}$, respectively.
Supplementation with FM had no effect on the activity of SOD in plasma, erythrocytes, ruminal fluid and mammary tissue, with values that averaged, respectively, 0.13, 16.33, 11.58 and $33.71 \mu \mathrm{mol} / \mathrm{min}$ per $\mathrm{mg}$ protein. The values of GPx activity were similar among the diets and averaged 33.68 and $1.18 \mathrm{nmol} / \mathrm{min}$ per $\mathrm{mg}$ protein in mammary tissue and erythrocytes, respectively. However, there was an interaction $(P=0.03)$ between treatment and time (Fig. 2(a)) for plasma GPx activity. There were quadratic $(P=0.002)$ and cubic $(P=0.007)$ effects of FM supplementation at $0 \mathrm{~h}$ and contrasts were not significant at $3 \mathrm{~h}$ after feeding.

The activity of CAT was not altered by the treatments in mammary tissue and erythrocytes, and values averaged 47.9 and $207.9 \mu \mathrm{mol} / \mathrm{min}$ per $\mathrm{mg}$, respectively. There was an interaction $(P=0.04)$ between treatment and time for CAT activity in plasma (Fig. 2(b)). Immediately before feeding, there were quadratic $(P=0.01)$ and cubic $(P=0.01)$ effects of FM supplementation, but no effect of FM supplementation $(P>0 \cdot 10)$ at $3 \mathrm{~h}$ post-feeding.

There was a trend for an overall treatment effect $(P=0 \cdot 10)$ for NFE2L2 mRNA abundance in mammary tissue, with a linear $(P=0.03)$ increase with FM supplementation (Fig. 3). A linear tendency was also observed for the CAT gene, with increasing mRNA abundance values observed with higher concentrations of FM ( $P=0 \cdot 09$; data not shown). The mRNA abundance of the CAT, GPX1, GPX3, SOD1, SOD2, SOD3 and $N F K B$ genes was not affected by the treatment.
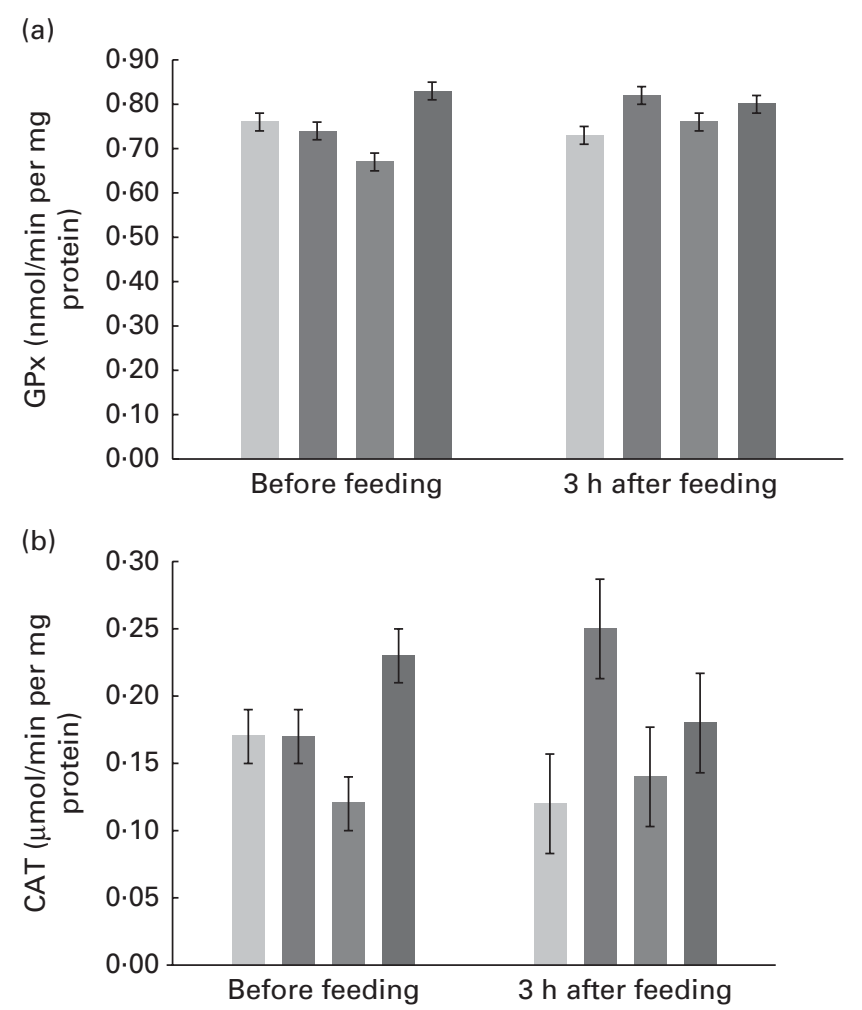

Fig. 2. Activity of (a) glutathione peroxidase (GPx) and (b) catalase (CAT) in the plasma of Holstein cows fed no flax meal (CON, 1 ) or $5 \%$ flax meal (5FM, $\square), 10 \%$ FM (10FM, $\square$ ) and 15\% FM (15FM, $\square)$ in the diet. Values are means, with their standard errors represented by vertical bars. There was an interaction between treatment and time for plasma GPx and CAT activities ( $P=0.03$ and 0.04 , respectively). 


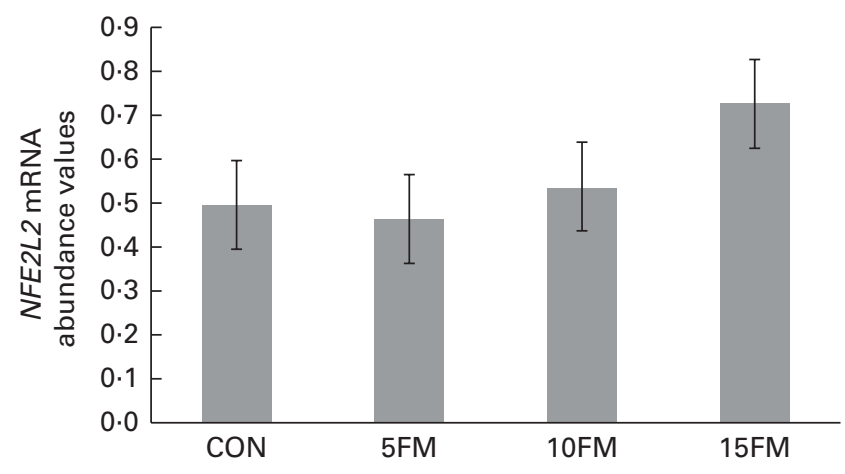

Fig. 3. Relative mRNA abundance of the nuclear factor (erythroid-derived 2)like 2 (NFE2L2) gene in the mammary tissue of Holstein cows fed no flax meal (CON) or $5 \%$ flax meal (5FM), $10 \%$ FM (10FM) and 15\% FM (15FM) in the diet. Values are least-squares means of seven animals from the analysis performed in triplicate, with their standard errors represented by vertical bars. There was a tendency for an overall effect of FM on NFE2L2 mRNA abundance $(P=0.10$; linear effect of treatment at $P=0.03)$.

\section{Discussion}

The oxidative status of dairy cows was monitored in the present study by the production of TBARS, which represents the peroxidation of lipids. Malondialdehyde production quantified through the TBARS assay is one of the biomarkers of damage caused in the body by reactive oxygen and nitrogen substances $^{(28)}$. FM-supplemented cows presented a linear reduction in the TBARS of ruminal fluid $2 \mathrm{~h}$ post-feeding, but the treatments had no effect after $2 \mathrm{~h}$ of feeding. According to Sadeghian \& Kojouri ${ }^{(29)}$, a greater period of time required to reach basal levels of malondialdehyde depends upon antioxidant supplementation and could indicate enhanced antioxidant activity. Therefore, this could suggest that within the first few hours (i.e. $<4 \mathrm{~h}$ ) of feed consumption, antioxidants present in FM may have contributed to the protection of dietary lipids against oxidation in the rumen as suggested by the linear decrease in TBARS with the inclusion of FM in the diet. Indeed, FM supplementation increases concentrations of the mammalian lignan enterolactone in the rumen, milk and urine ${ }^{(11)}$, and previous results have shown that antioxidant activity of mammalian lignans is greater than that of vitamin $\mathrm{E}^{(12)}$.

The production of TBARS was lower in the milk of cows fed the 5FM and 10FM diets than in the milk of those fed the CON and 15FM diets, and there was no difference among the treatments for TBARS production in plasma. However, all diets resulted in lower plasma TBARS production after feeding, which can be associated with the consumption of certain feed ingredients. Indeed, many feedstuffs contain glutathione, tocopherols, ascorbate, uric acid and $\beta$-carotene, which may improve plasma non-enzymatic antioxidant indicators ${ }^{(28)}$. Moreover, the greatest proportion of vitamins in the diet of cows fed 15FM probably increased the consumption of vitamin E, which is a strong antioxidant and may have influenced TBARS production.

Radical-scavenging activity was assessed by the DPPH assay, which measures modifications in antioxidant activity ${ }^{(20)}$. Supplementation with FM had no effect on DPPH determined in milk, plasma and ruminal fluid, although there was a time effect in ruminal fluid. According to the method used in the present study and described previously by Smet et al. ${ }^{(23)}$, the lower the $\mathrm{EC}_{50}$ value, the higher the content of antioxidants. To our knowledge, only two studies have previously observed an increase in the antioxidant activity of ruminal fluid measured by the DPPH method $2 \mathrm{~h}$ after feeding. The first one is that of Gizi et al. ${ }^{(30)}$ who compared faunated $v$. defaunated cattle (protozoa-free) and the second one is that of Aoki et al. ${ }^{(31)}$ who supplemented cows with trehalose and cellobiose, two disaccharides with and without antioxidant activity, respectively. According to Gizi et al. ${ }^{(30)}$, the level of antioxidants in ruminal fluid increases due to the supply of lipids or fat-soluble compounds that contain carotenoids and vitamins, and/or to antioxidants obtained from the metabolism of ruminal micro-organisms. In the present study, a similar increase in antioxidant activity was observed in ruminal fluid after feeding, although this occurred regardless of the treatment, thus corroborating the results of Gizi et $a l{ }^{(30)}$ that distinct nutrients and the microbial production of antioxidants may be responsible for increased antioxidant activity in ruminal fluid.

SOD is considered the first intracellular defence against reactive oxygen molecules ${ }^{(32)}$. This enzyme causes a dismutation of the superoxide anion radical to $\mathrm{H}_{2} \mathrm{O}_{2}{ }^{(28)}$, which is further degraded by CAT and peroxidase actions. In the present study, the addition of FM had no effect on the activity of SOD. These results then may suggest that the same amount of $\mathrm{H}_{2} \mathrm{O}_{2}$ was produced in the body fluids and tissues of animals fed or not FM. According to Hosada et al. ${ }^{\text {(33) }}$, a lack of alteration in antioxidant enzymes could be due to a sufficient pool of non-enzymatic antioxidant substances probably present in the defence system of ruminants. The activity of SOD in the plasma of dairy cows has been shown to increase with antioxidant supplementation, but the effect was dependent on the type of fat fed, with the highest activity being observed when oxidised fat was added to the diet ${ }^{(5)}$. This is corroborated with the fact that supplementation of non-oxidised lipids in the form of flax oil infusion in the abomasum has no effect on SOD activity in the plasma, erythrocytes and mammary tissue of dairy cows ${ }^{(14)}$.

The interaction between treatment and time for plasma GPx activity before feeding was probably due to lower activity when cows were fed the 10FM diet and higher activity for those fed the 15FM diet. The higher values of GPx activity in plasma maintained with the 15FM diet may suggest that a proportion of $15 \mathrm{FM}$ in the diet may provide enough antioxidants to improve the oxidative status of cows. An increase in the plasma GPx activity of dairy cows has also been observed by Vázquez-Añón et al. ${ }^{(5)}$ who fed diets containing antioxidants and oxidised or non-oxidised soyabean oil. Wullepit et $a l{ }^{\left({ }^{(34)}\right.}$ fed marine algae (source of $n$-3 fatty acids) to cows, and they have attributed the increase in plasma GPx activity to the PUFA supply from algae and its induction of lipoperoxidation. On the other hand, Côrtes et al. ${ }^{(14)}$ observed a decrease in plasma GPx activity when they fed $n-3$ PUFA to lactating dairy cows. Taken altogether, these results have suggested that the ingestion of antioxidant 
compounds may act directly on the GPx enzyme system, where they can protect against plasma lipoperoxidation even when PUFA are supplied in the diet.

Similar responses of treatment over time were observed for both plasma GPx and CAT activities, which are enzymes degrading $\mathrm{H}_{2} \mathrm{O}_{2}$. According to Celi ${ }^{(35)}$, when SOD activity increases the production of $\mathrm{H}_{2} \mathrm{O}_{2}$, a protection from reactive oxygen substances would only be provided by a simultaneous increase in CAT and GPx activities and the availability of glutathione.

Supplementation with FM had no effect on SOD, CAT and GPx activities in mammary tissue and erythrocytes. Although erythrocytes are one rich source of antioxidant enzymes, they are also a significant source of superoxide generation in biological systems ${ }^{(28)}$. As the production of superoxide ions and oxygen peroxides occurs under oxidative stress ${ }^{(30)}$, this may suggest that the lack of a treatment effect on enzyme activities was a result of the cows that were in good health, mid-lactation and positive energy balance. Changes in the activity of erythrocyte antioxidant enzymes in dairy cattle have been reported only when animals were in the transition period, which may result from cows that are under oxidative stress $^{(1)}$.

In the present study, FM supplementation increased mammary NFE2L2 mRNA abundance, and had no effect on the mRNA abundance of the GPx1, GPx3, SOD1, SOD2, $S O D 3$ and NFKB genes. The NFE2L2 gene, also known as nuclear factor-E2-related factor 2 (Nrf2), encodes for a transcription factor that plays essential roles in cellular defence against oxidative stress ${ }^{(36)}$. This transcription factor activates the expression of a series of genes having an antioxidant response element in their promoters, including antioxidant proteins and phase 2 detoxifying enzymes ${ }^{(37,38)}$. Of interest, flax lignans are composed of polyphenolic compounds present in plants as glycoside conjugates ${ }^{(39)}$, and many natural polyphenol-containing compounds have the ability to modulate $N r f 2$-mediated cellular events ${ }^{(40,41)}$. The reason for the lack of the overall treatment effect of FM on the GPx1, GPX3, CAT, SOD1, SOD2 and SOD3 genes remains to be determined since SOD1, CAT and GPX are all considered as established $N r f 2$-regulated genes ${ }^{(42)}$. In a previous study, we have reported that cows fed $9.88 \%$ flax hulls, a rich source of the plant lignan secoisolariciresinol diglucoside, have higher levels of CAT, GPX1 and SOD1 mRNA in mammary tissue and lower mRNA abundance of GPx3, SOD2 and SOD3 than cows fed no flax hulls ${ }^{(14)}$. These discrepancies may be explained by the higher oil content found in flax hulls $(30 \%$ of diethyl ether extract in DM) compared with FM $(<5 \% \text { of residual oil content in DM })^{(16)}$. Since we have shown that flax oil modulates antioxidant enzyme mRNA abundance in the cow's mammary tissue, differences in the lipid content between flax hulls and FM may indeed account for some of the observed discrepancies between our data and those of Côrtes et al. ${ }^{(14)}$

In conclusion, the present study shows that FM supplementation can improve the oxidative status of Holstein cows in mid to late lactation, as suggested by decreased TBARS production in ruminal fluid $2 \mathrm{~h}$ post-feeding and increased
NFE2L2/Nrf2 mRNA abundance in mammary tissue. Further studies are required to clarify the role of FM on the oxidative status of cows during the transition and early lactation periods as cows are more prone to oxidative stress during these periods. Any beneficial effects of FM on the oxidative status of cows could lead to a prophylactic strategy against diseases affecting the health status of dairy cattle.

\section{Acknowledgements}

A. L. B. S. was recipient of a studentship from the National Council of Technological and Scientific Development (CNPq), Brazil. The authors express their gratitude to the staff of the Agriculture and Agri-Food Canada for their contribution to the present study, especially L. Veilleux, D. Beaudry and N. Gagnon for technical assistance and S. Méthot for his help in statistical analysis. The present study was sponsored by the Agriculture and Agri-Food Canada. The authors' contributions were as follows: A. L. B. S., M.-F. P. and H. V. P. drafted the manuscript; H. V. P. and M.-F. P. conceived and directed the study; A. L. B. S. coordinated the study, was in charge of collecting the animal data and performed the laboratory work on enzyme and antioxidant activities; G. T. d. S. participated in the design of the study; C. B. contributed to the conception and design of the experiment; P. L. performed the mammary biopsies. All authors critically revised the paper and approved the final version of the manuscript. None of the authors had a personal or professional conflict of interest.

\section{References}

1. Bernabucci U, Ronchi B, Lacetera N, et al. (2005) Influence of body condition score on relationships between metabolic status and oxidative stress in periparturient dairy cows. J Dairy Sci 88, 2017-2026.

2. Castillo C, Hernandez J, Bravo A, et al. (2005) Oxidative status during late pregnancy and early lactation in dairy cows. Vet J 169, 286-292.

3. Gobert M, Martin B, Ferlay A, et al. (2009) Plant polyphenols associated with vitamin $\mathrm{E}$ can reduce plasma lipoperoxidation in dairy cows given $n$-3 polyunsaturated fatty acids. J Dairy Sci 92, 6095-6104.

4. Miller JK, Brzezinska-Slebodzinska E \& Madsen FC (1993) Oxidative stress, antioxidants and animals function. J Dairy Sci 76, 2812-2823.

5. Vázquez-Añón M, Nocek J, Bowman G, et al. (2008) Effects of feeding a dietary antioxidant in diets with oxidized fat on lactation performance and antioxidant status of the cow. J Dairy Sci 91, 3165-3172.

6. Frankel EN (2005) Lipid Oxidation [EN Frankel, editor]. Bridgwater: The Oily Press.

7. Megahed GA, Anwar MM, Wasfy SI, et al. (2008) Influence of heat stress on the cortisol and oxidant-antioxidants balance during oestrous phase in buffalo-cows (Bubalus bubalis): thermo-protective role of antioxidant treatment. Reprod Dom Anim 43, 672-677.

8. Aitken SL, Karcher EL, Rezamand P, et al. (2009) Evaluation of antioxidant and proinflammatory gene expression in bovine mammary tissue during the periparturient period. J Dairy Sci 92, 589-598.

9. Prasad K (1997) Dietary flax seed in prevention of hypercholesterolemic atherosclerosis. Atherosclerosis 132, 69-76. 
10. Milder IEJ, Arts ICW, Van De Putte B, et al. (2005) Lignan contents of Dutch plant foods: a database including lariciresinol, pinoresinol, secoisolariciresinol and matairesinol. $\mathrm{BrJ}$ Nutr 93, 393-402.

11. Gagnon N, Côrtes C, Da Silva D, et al. (2009) Ruminal metabolism of flaxseed Linum usitatissimum lignans to the mammalian lignan enterolactone and its concentration in ruminal fluid, plasma, urine and milk of dairy cows. $\mathrm{Br} \mathrm{J}$ Nutr 102, 1015-1023.

12. Prasad K (2000) Antioxidant activity of secoisolariciresinol diglucoside-derived metabolites, secoisolariciresinol, enterodiol, and enterolactone. Int J Angiol 9, 220-225.

13. Pool-Zobel BL, Adlercreutz H, Glei M, et al. (2000) Isoflavonoids and lignans have different potentials to modulate oxidative genetic damage in human colon cells. Carcinogenesis 21, 1247-1252.

14. Côrtes C, Palin MF, Gagnon N, et al. (2012) Mammary gene expression and activity of antioxidant enzymes and concentration of the mammalian lignan enterolactone in milk and plasma of dairy cows fed flax lignans and infused with flax oil in the abomasum. Br J Nutr 108, 1390-1398.

15. Rajesha J, Murthy KNC, Kumar MK, et al. (2006) Antioxidant potentials of flaxseed by in vivo model. J Agric Food Chem 54, 3794-3799.

16. Newkirk R (2008) Flax Feed Industry Guide. Winnipeg, MB: Flax Canada 2015.

17. National Research Council (2001) Nutrient Requirements of Dairy Cattle, 7th rev. ed. Washington, DC: National Academic Press.

18. Canadian Council on Animal Care (1993) Guide to Care and Use of Experimental Animal [ED Offert, BM Cross and AA McWilliam, editors]. Ottawa, ON: CCAC.

19. Farr VC, Stelwagen K, Cate LR, et al. (1996) An improved method for the routine biopsy of bovine mammary tissue. J Dairy Sci 79, 543-549.

20. Brand-Williams W, Cuvelier ME \& Berset C (1995) Use of a free radical method to evaluate antioxidant activity. Lebensm Wiss Technol 28, 25-30.

21. Martinez S, Valek L, Resetic J, et al. (2006) Cyclic voltammetry study of plasma antioxidant capacity - comparison with the DPPH and TAS spectrophotometric methods. $J$ Electroanal Chem 588.

22. Li W, Hosseinian FS, Tsopmo A, et al. (2009) Evaluation of antioxidant capacity and aroma quality of breast milk. Nutrition 25, 105-114

23. Smet K, Raes K, De Block J, et al. (2008) A change in antioxidative capacity as a measure of onset to oxidation in pasteurized milk. Int Dairy J 18, 520-530.

24. Labrecque B, Beaudry D, Mayhue M, et al. (2009) Molecular characterization and expression analysis of the porcine paraoxonase 3 (PON3) gene. Gene 443, 110-120.

25. Andersen CL, Jensen JL \& Orntoft TF (2004) Normalization of real-time quantitative reverse transcription-PCR data: a model-based variance estimation approach to identify genes suited for normalization, applied to bladder and colon cancer data sets. Cancer Res 64, 5245-5250.

26. Biosystems A. Series ABI PRISM 7700 Sequence Detection System (1997) ABI PRISM 7700 Sequence Detection System. In User Bulletin \#2. Applied Biosystems, Foster City, CA.
27. Barret PM, Dadds MR \& Rapee RM (1996) Family treatment of childhood anxiety: a controlled trial. J Consult Clin Psychol 64, 333-342.

28. Vasconcelos SML, Goulart MOF, Moura JBF, et al. (2007) Reactive oxygen and nitrogen species, antioxidants and markers of oxidative damage in human blood: main analytical methods for their determination. Quim Nova 30, 1323-1338.

29. Sadeghian S \& Kojouri GA (2012) Nanoparticles of selenium as species with stronger physiological effects in sheep in comparison with sodium selenite. Biol Trace Elem Res 146, 302-308.

30. Gizi A, Papassotiriou I, Apostolakou F, et al. (2011) Assessment of oxidative stress in patients with sickle cell disease: the glutathione system and the oxidant-antioxidant status. Blood Cell Mol Dis 46, 220-225.

31. Aoki N, Furukawa S, Sato K, et al. (2010) Supplementation of the diet of dairy cows with trehalose results in milk with low lipid peroxide and high antioxidant content. J Dairy Sci $\mathbf{9 3}$, 4189-4195.

32. Adela P, Zinveliu D, Pop RA, et al. (2006) Antioxidant status in dairy cows during lactation. Buletin USAMV-CN 63, $130-135$.

33. Hosada K, Miyaji M, Matsuyama H, et al. (2012) Effect of supplementation of purple pigment from anthocyanin-rich corn (Zea mays L.) on blood antioxidant activity and oxidation resistance in sheep. Livest Sci 145, 266-270.

34. Wullepit N, Hostens M, Ginnenberge C, et al. (2012) Influence of marine algae supplementation on the oxidative status of plasma in dairy cows during the peripartum period. Prev Vet Med 130, 298-303.

35. Celi $\mathrm{P}$ (2010) The role of oxidative stress in small ruminants' health and production. Revta Bras Zootec 39, 348-363.

36. Nguyen T, Nioi P \& Pickett CB (2006) The Nrf2-antioxidant response element signaling pathway and its activation by oxidative stress. J Biol Chem 284, 13291-13295.

37. Kang KW, Lee SJ \& Kim SG (2005) Molecular mechanism of Nrf2 activation by oxidative stress. Antioxid Redox Signal 7, $1664-1673$.

38. Zhu H, Itoh K, Yamamoto $\mathrm{M}$, et al. (2005) Role of Nrf2 signaling in regulation of antioxidants and phase 2 enzymes in cardiac fibroblasts: protection against reactive oxygen and nitrogen species-induced cell injury. FEBS Lett 579, 3029-3036.

39. Hu C, Yuan YV \& Kitts DD (2007) Antioxidant activities of the flaxseed lignan secoisolariciresinol diglucoside, its aglycone secoisolariciresinol and the mammalian lignans enterodiol and enterolactone in vitro. Food Chem Toxicol 45, 2219-2227

40. Na HK \& Surh YJ (2008) Modulation of Nrf2-mediated antioxidant and detoxifying enzyme induction by the green tea polyphenol EGCG. Food Chem Toxicol 46, 1271-1278.

41. Martin MA, Ramos S, Granado-Serrano AB, et al. (2010) Hydroxytyrosol induces antioxidant/detoxificant enzymes and Nrf2 translocation via extracellular regulated kinases and phosphatidylinositol-3-kinase/protein kinase B pathways in HepG2 cells. Mol Nutr Food Res 54, 956-966.

42. Chen XL \& Kunch C (2004) Induction of cytoprotective genes through Nrf2/antioxidant response element pathway: a new therapeutic approach for the treatment of inflammatory diseases. Curr Pharm Des 10, 879-891. 